\title{
Alat Pengatur Takaran Pakan Ikan Otomatis Menggunakan Metoda Fuzzy dengan Sensor Suhu dan $\mathrm{pH}$
}

\author{
Anton Hidayat ${ }^{1}$, Rifky Darmansyah ${ }^{2}$, Junaldi ${ }^{3}$, Nasrullah ${ }^{4}$ \\ ${ }^{1234}$ Elektronika Industri, Politeknik Negeri Padang \\ Jurusan Teknik Elektro Politeknik Negeri Padang, Jl. Limau Manih Padang, 25164, Indonesia \\ Coreponding Author, email:Antonramiati @gmail.com
}

\begin{abstract}
Abstrak - Kesibukan seperti bekerja, keluar kota, liburan bersama keluarga membuat sulitnya pemberian pakan ikan di lakukan dengan baik karena pembudidaya tidak bisa selalu berada di dekat kolam. Di tambah lagi cuaca yang tidak menentu yang dapat menurunkan kualitas air kolam sehingga takaran pakan harus di sesuaikan kembali dari takaran normalnya. Pemberian pakan ikan dapat di lakukan otomatis dengan membuat alat pemberi pakan secara terjadwal dan terukur dengan menggunakan RTC, keypad dan lcd sebagai antarmuka dengan pengguna. Dan di gunakan metoda fuzzy untuk menyesuaikan takaran pakan berdasarkan nilai suhu dan pH air kolam. Kemudian di ukur menggunakan putaran ulir serta encoder agar mengetahui banyaknya putaran ulir yang di lakukan. Setelah di lakukan pengujian, di peroleh bahwa alat ini dapat memberikan pakan ikan sesuai jadwal dengan takaran rata-rata sebanyak 302,6 gr setiap 100 putaran ulir dengan error banyak pakan yang keluar sebesar $1.03 \%$ dalam selang waktu 5.77 detik.
\end{abstract}

Kata kunci: Takaran, ulir, encoder,pakan ikan.

Abstract-Busy activities, such as working, going out of town, holidays with family, make any difficulty in providing of the fish because farmers of the fish are not always near the pond. Furthermore, the erratic weather can reduce the quality of pond water. It makes a dose of fish feed needs to be adjusted again form the regular dose. Fish feeding can be done automatically by creating a scheduled and measured feeder equipment using RTC, keypad, and LCD as an interface with the user of fish farmers. Besides, this tool also facilitated with fuzzy logic Algorithm to adjust the feed dose based on the temperature and $\mathrm{pH}$ value of the pond water. Feeding of the fish is measured using a thread rotation and encoder for measures the value of thread rotation when the feeding process happens. The experiment result obtained that this tool can provide fish feed on schedule with an average dose of 302,6 $\mathrm{g}$ per 100 turns of a thread with error feeding around 1,03\% in 5,77 seconds.

Keywords: dose, screw, encoder, fish feed.

(C) 2020 Elektron Jurnal Ilmiah

\section{PENDAHULUAN}

Kesibukan seperti bekerja, keluar kota, liburan bersama keluarga membuat sulitnya pemberian pakan ikan di lakukan dengan baik karena pembudidaya tidak bisa selalu berada di dekat kolam. Di tambah lagi cuaca yang tidak menentu yang dapat menurunkan kualitas air kolam sehingga nafsu makan ikan pun juga berubah. Nafsu makan ikan dapat bergantung pada suhu dan $\mathrm{pH}$ air. Pada saat suhu air tidak sesuai dengan dengan suhu optimal hidup ikan, membuat nafsu makan ikan berkurang dimana suhu air yang sesuai untuk ikan air tawar antara $25-30$ derajat celcius. Sementara disaat nilai $\mathrm{pH}(>8)$ akan meningkatkan kandungan ammonia dalam air dan menyebabkan ikan tak nafsu makan dimana $\mathrm{pH}$ air untuk habitat lele antara 6,5-8 [12].

Untuk itu pengaturan takaran pakan ikan sangat di perlukan agar takaran pakan ikan yang di berikan sesuai dengan tingkat nafsu ikan. Salah satu cara atau metoda agar takaran pakan sesuai dengan tingkat nafsu ikan ialah dengan menggunakan metoda fuzzy[1,11,18]. Untuk itu penelitian ini di lakukan agar dapat memberikan pakan ikan sesuai dengna takaran yang diperlukan berdasarkan kondisi suhu dan air kolam[19].

Pada penelitian lainnya yang di lakukan Agus waluyo [15] yang dibuatnya menggunakan servo sebagai pengatur takaran pakan. Sehingga servo akan membuka dan menutup sesuai dengan banyak takaran yang di atur. Namun pada penelitian ini tidak menggunakan metoda apapun untuk menakar pakan sesuai dengan kondisi air kolam.

Penggunaan servo sebagai pengatur takaran pakan ikan yang keluar memiliki kelemahana dalam segi keakurasian pakan ikan yang keluar dan ketahanan penggunaan servo dalam jangka waktu yang panjang. Untuk itu dalam penelitian yang penulis lakukan, penggunaan servo di ganti menjadi besi ulir. Dimana banyak nya putaran ulir akan menjadi acuan tentang banyaknya pakan ikan yang keluar [4,5].

Banyaknya putaran ulir dapat di ketahui dengan menggunakan encoder untuk membaca putara dari ulir tersebut. Pada penelitian ini akan di teliti berapa banyaknya ulir perlu berputar untuk mendapatkan berat pakan ikan yang di inginkan 
Kemudian respon makan ikan terhadap lingkungannya dapat di lihat pada nilai suhu dan $\mathrm{pH}$ air. Respon nafsu makan ikan terhadap suhu air dapat di lihat pada tabel 1 . Berikut.

Tabel 1. Respon nafsu makan ikan terhadap suhu air

\begin{tabular}{cl}
\hline $\begin{array}{c}\text { Suhu Air } \\
\left({ }^{\circ} \mathbf{C}\right)\end{array}$ & \multicolumn{1}{c}{ Respon kosumsi pakan } \\
\hline Mendekati 0 & Kondisi kritis minimal \\
\hline $8-10$ & Tidak ada respon terhadap pemberian pakan \\
\hline 15 & Pemeberian pakan berkurang \\
\hline 22 & $50 \%$ optimum \\
\hline $28-30$ & Pemberian pakan optimum \\
\hline 33 & $50 \%$ optimum \\
\hline 35 & Pemberian pakan berkurang \\
\hline $36-38$ & Tidak respon terhadap pemberian pakan \\
\hline $38-42$ & Kondisi kritis minimal \\
\hline
\end{tabular}

Berdasarkan penelitian yang di lakukan oleh Tucker dan Hargreaves [14] bahwa optimalisasi konsumsi pakan ikan akan berkurang di luar rentangan suhu 28-30 derajat celcisus. Tujuan penelitian ini adalah untuk menciptakan alat takar pakan ikan otomatis dengan pewaktu yang telah ditentukan serta takaran makan sesuai kebutuhan ikan

\section{METODE}

Dalam pembuatan alat ini digunakan 6 input dan 4 output yang semuanya dikendalikan oleh mikrokontroller Arduino uno [2,7]. Blok diagram dari alat ini secara keseluruhan dapat di lihat pada gambar 1. Sensor DS18B20 berfungsi untuk mendeteksi suhu air kolam, untuk mengukur kadar PH digunakan sensor PH Diymore 4502C, Real Time Clock (RTC) berfungsi sebagai pewaktuan untuk pemberian pakan secara terjadwal dan terukur. Untuk mengatur berapa jumlah makanan ikan digunakan keypad, saklar tekan berfungsi untuk mengantisipasi jika system control tidak berfungsi. Rangkaian encoder berfungsi untuk menghitung banyaknya putaran ulir. Semua pembacaan sensor dan inputan dari keypad dikirimkan ke mikrokontroler. Hasil proses di mikrokontroler kemudian ditampilkan pada LCD dan aplikasi smartphone. I2C LCD digunakan menampilkan nilai detak jantung pada LCD, modul ini dikendalikan secara serial sinkron dengan protocol I2C/IIC (inter integrated circuit) atau TWI (Two Wire interface) dengan alamat 0x27 dan 0x37. Modul wifi nodemcu 8266 digunakan untuk mengirimkan data dari mikrokontroler ke server Thingspeak.com dengan menggunakan protocol TCP/IP untuk komunikasi. Untuk mengerakkan ulir pada makanan ikan digunakan dua buah Motor DC.

Selanjutnya dilakukan perancangan software. Dalam perancangan dan pembuatan perangkat lunak (software) pada penelitian ini, komunikasi sensor dengan mikrokontroler dan seluruh proses menggunakan bahasa C software arduino IDE. Diagram alir atau flowchart system alat ini dapat dilihat pada gambar 2 .
Proses dimulai dari inisialiasi RTC, sensor suhu, sensor $\mathrm{pH}$, fuzzy, saklar dan motor. Selanjutnya pengiriman data input (RTC, sensor suhu,sensor $\mathrm{pH}$ dan data berat. Data-data input tersebut ditampilkan ke LCD dan dikirimkan ke webserver. Pada saat proses setting makanan untuk ikan akan dibandingkan nilai RTC. Jika nilai RTC sama dengan nilai setting waktu maka proses fuzzy logic dijalankan dan akan menghitung banyaknya putaran motor

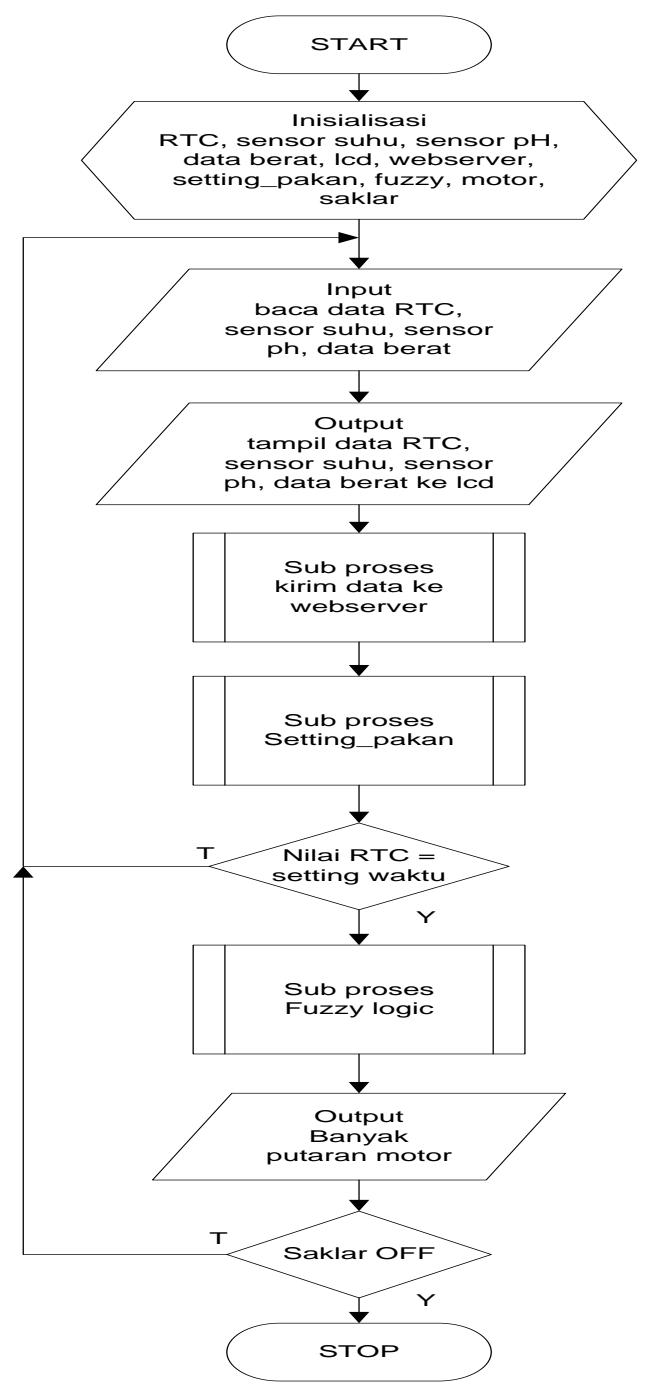

Gambar 2. Flowchar system keseluruhan

Diantara 6 input terdapat 2 input yang digunakan sebagai input metoda fuzzy seperti yang di jabarkan pada blok diagram pada gambar 3 . 


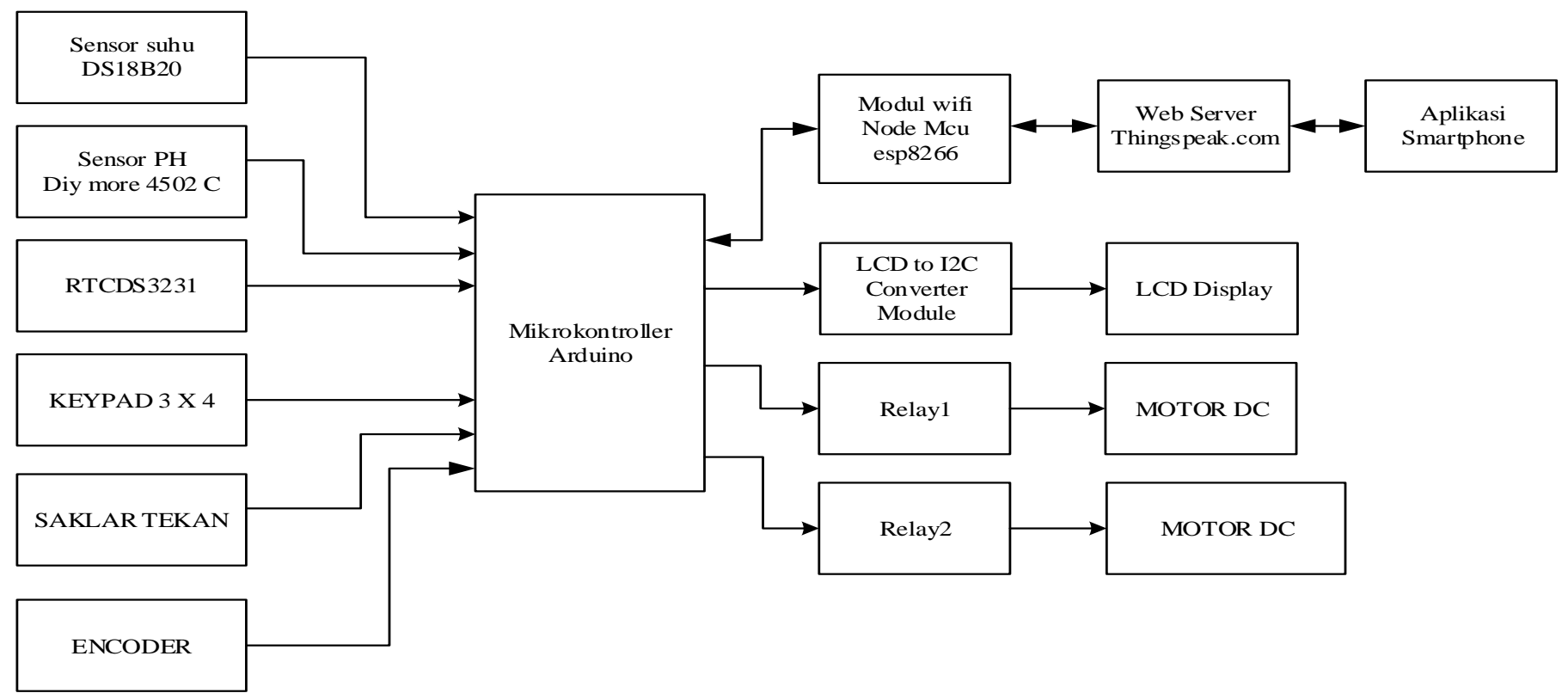

Gambar 1. Blok Diagram Alat

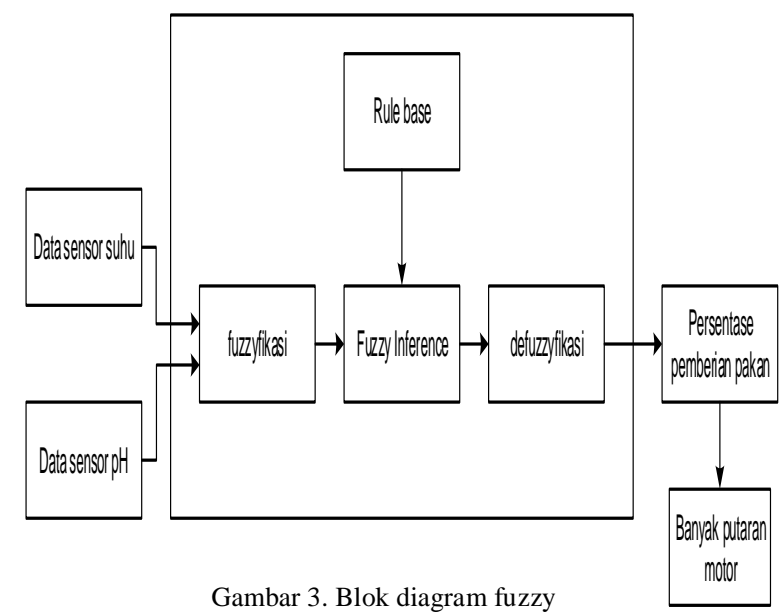

Dalam metoda fuzzy di gunakan 2 input yaitu sensor suhu dan $\mathrm{pH}$, dimana pada proses fuzzyfikasi di dapati fungsi keanggotaan masing masing input yang di sesuaikan dengan grafik.. Grafik sensor suhu yang di dasari pada Tabel 1 dapat di lihat pada gambar 4.

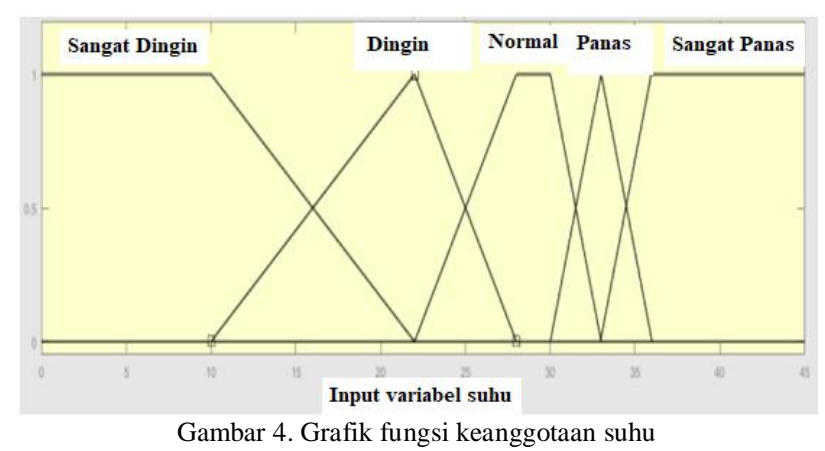

Kemudian input kedua yaitu sensor $\mathrm{pH}$ memiliki grafik fungsi keanggotaan seperti gambar 5 berikut

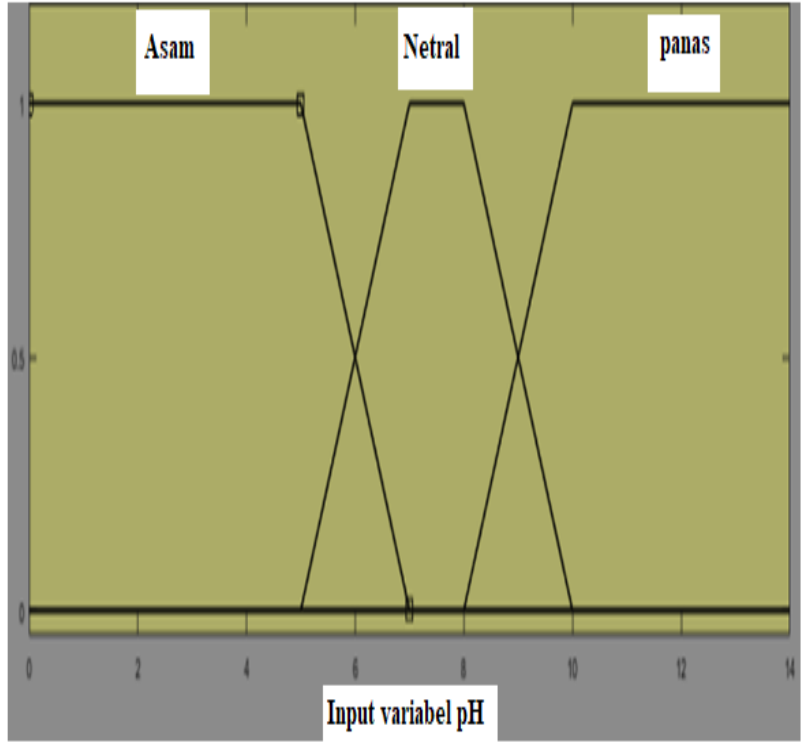

Gambar 5 . Grafik fungsi keanggotan $\mathrm{pH}$

Output pada sistem ini berupa persentase pemberian pakan dari banyak pakan saat kondisi normal. Dimana fungsi keanggotaan output dibagi menjadi 3 bagian yaitu optimal pada 100 persen, kurang optimal dengan nilai 50 persen dan tidak optimal dengan nilai 0 persen. Grafik fungsi keanggotaan output dapat dilihat pada gambar 6 . 


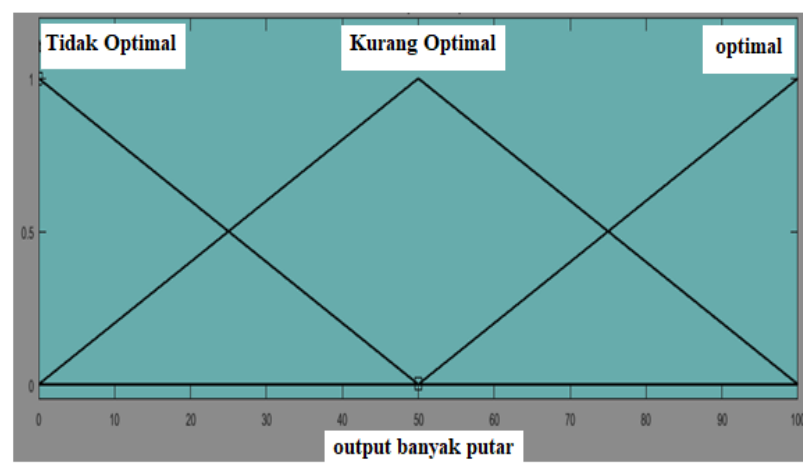

Gambar 6. Blok diagram fuzzy

Setelah pembuatan fungsi keanggotaan, selanjutnya penentuan aturan dasar dari metoda fuzzy. Seperti pada Tabel 2 berikut.

Tabel 2. penentuan aturan dasar dari metoda fuzzy

\begin{tabular}{|c|c|c|c|c|c|}
\hline & $\begin{array}{l}\text { Sangat. } \\
\text { Dingin }\end{array}$ & Dingin & Normal & Panas & $\begin{array}{c}\text { Sangat. } \\
\text { Panas }\end{array}$ \\
\hline Asam & $\begin{array}{c}\text { T.Opti } \\
\text { mal }\end{array}$ & $\begin{array}{c}\text { T. } \\
\text { Optim } \\
\text { al }\end{array}$ & $\begin{array}{c}\text { K.Opti } \\
\text { mal }\end{array}$ & $\begin{array}{c}\text { K.Opti } \\
\text { mal }\end{array}$ & T.Optimal \\
\hline Netral & $\begin{array}{c}\text { T.Opti } \\
\text { mal }\end{array}$ & $\begin{array}{c}\text { K.Opti } \\
\text { mal }\end{array}$ & Optimal & $\begin{array}{c}\text { K.Opti } \\
\text { mal }\end{array}$ & T.Optimal \\
\hline Basa & $\begin{array}{c}\text { T.Opti } \\
\text { mal }\end{array}$ & $\begin{array}{c}\text { T.Opti } \\
\text { mal }\end{array}$ & $\begin{array}{c}\text { K.Opti } \\
\text { mal }\end{array}$ & $\begin{array}{c}\text { K.Opti } \\
\text { mal }\end{array}$ & T.Optimal \\
\hline
\end{tabular}

Nilai dari output kemudian di konversikan menjadi banyaknya putaran ulir menggunakan persamaan linearisasi. Banyaknya putaran ulir akan menghasilkan banyaknya takaran pakan ikan yang keluar. Banyaknya putaran ulir dapat di hitung dengan menggunakan encoder sebagai perubah putaran menjadi nilai bilangan bulat. Encoder disini menggunakan sensor photodiode yang menangkap pantulan cahaya dari pembatas berwarna putih yang di letakkan pada ulir yang berputar. Rangkaian encoder tersebut dapat dilihat pada gambar 7 berikut.

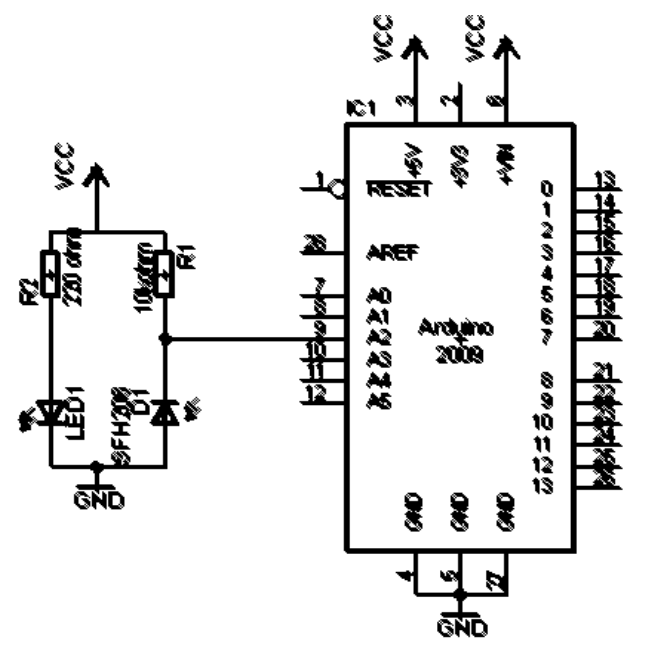

Gambar 7. Rangkaian encoder

\section{HASIL DAN PEMBAHASAN}

Hasil dari penelitian alat di dapati data pembahasan dimana Pokok-pokok pembahasan yang dilakukan dalam tahap pengujian ini adalah sebagai berikut :
A. Pengujian sensor $\mathrm{pH}$
B. Pengujian sensor suhu DS18B20
C. Pengujian putaran ulir dengan takaran pakan
D. Pengujian kendali fuzzy
E. Pengujian penampilan data pada aplikasi android

\section{A. Pengujian sensor $\mathbf{p H}$}

Uji banding sensor $\mathrm{pH} 4502 \mathrm{C}$ dengan alat ukur $\mathrm{pH}$ meter di gunakan untuk membandingkan data nilai sensor dengan alat ukur sehingga dapat di ketahui apakah hasil dari sensor $\mathrm{pH}$ yang di gunakan akurat sesuai dengan data sebenarnya. Dari proses pengambilan data yang di lakukan di dapatkan hasil seperti tabel 3 berikut:

Tabel 3. Uji sensor $\mathrm{pH}$ dengan alat $\mathrm{pHmeter}$

\begin{tabular}{c|c|c|c|c|c|c}
\hline Jenis air & $\begin{array}{c}\text { Phmet } \\
\text { er }\end{array}$ & $\begin{array}{c}\text { Sens } \\
\text { orpH }\end{array}$ & $\begin{array}{c}\text { Tegan } \\
\text { gan }\end{array}$ & ADC & $\begin{array}{c}\text { Err } \\
\text { or }\end{array}$ & $\%$ Error \\
\hline $\begin{array}{c}\text { Air } \\
\text { cuka }\end{array}$ & 3.1 & 3.06 & $3.22 \mathrm{v}$ & 659 & 0.0 & 1.290 \\
\hline $\begin{array}{c}\text { Air } \\
\text { lemon }\end{array}$ & 4.1 & 3.95 & $3.07 \mathrm{v}$ & 628 & 0.1 & 3.658 \\
\hline $\begin{array}{c}\text { Larutan } \\
\text { pH4 }\end{array}$ & 4.3 & 4.17 & $3.03 \mathrm{v}$ & 620 & 0.1 & 3.023 \\
\hline $\begin{array}{c}\text { Air } \\
\text { sumur }\end{array}$ & 6.4 & 6.57 & $2.61 \mathrm{v}$ & 534 & 0.1 & 2.656 \\
\hline $\begin{array}{c}\text { larutan } \\
\text { garam }\end{array}$ & 6.7 & 6.74 & $2.58 \mathrm{v}$ & 528 & 0.1 & 0.597 \\
\hline $\begin{array}{c}\text { Larutan } \\
\text { pH6.8 }\end{array}$ & 6.8 & 6.98 & $2.53 \mathrm{v}$ & 518 & 0.2 & 2.647 \\
\hline $\begin{array}{c}\text { Air } \\
\text { Kolam }\end{array}$ & 7.3 & 7.23 & $2.49 \mathrm{v}$ & 509 & 0.1 & 0.958 \\
\hline $\begin{array}{c}\text { Air } \\
\text { sabun }\end{array}$ & 9.8 & 9.42 & $2.11 \mathrm{v}$ & 432 & 0.4 & 3.877 \\
\hline $\begin{array}{c}\text { Air } \\
\text { deterjen }\end{array}$ & 9.9 & 10.3 & $1.94 \mathrm{v}$ & 397 & 0.4 & 4.545 \\
\hline \begin{tabular}{c} 
Rata-rata \\
\hline
\end{tabular}
\end{tabular}

Setelah melakukan pengujian sebanyak 9 kali dengan air yang berbeda beda, dapat di hitung nilai rata-rata error sebesar 0.17 dan dapat di katakan bahwa hasil penggunaan sensor $\mathrm{pH}$ dengan alat ukur $\mathrm{pH}$ meter efektif karena nilai error di dapatkan kurang dari 1 dengan error rata-rata $2,77 \%$.

\section{B. Pengujian sensor suhu}

Uji banding sensor suhu dengan alat ukur di gunakan untuk membandingkan data sensor suhu dengan alat ukur sebenarnya sehingga dapat di ketahui apakah hasil dari sensor suhu yang di gunakan akurat dan sesuai dengan data yang sebenarnya. Dari pengujian yang di lakukan di dapatkan hasil seperti Tabel.4 berikut 
Tabel 4. Uji banding sensor suhu dengan thermometer

\begin{tabular}{cccc}
\hline $\begin{array}{c}\text { Alat ukur } \\
(\square \mathrm{C})\end{array}$ & $\begin{array}{c}\text { Sensor suhu } \\
\left({ }^{\circ} \mathrm{C}\right)\end{array}$ & Error & \%Error \\
\hline 25.6 & 25.81 & 0.21 & 0.8203125 \\
\hline 26.5 & 26.62 & 0.12 & 0.452830189 \\
\hline 26.5 & 26.75 & 0.25 & 0.943396226 \\
\hline 26.9 & 27 & 0.1 & 0.371747212 \\
\hline 27.9 & 28.1 & 0.2 & 0.716845878 \\
\hline 28.2 & 28.37 & 0.17 & 0.602836879 \\
\hline 29.1 & 29.19 & 0.09 & 0.309278351 \\
\hline 30 & 30.21 & 0.21 & 0.7 \\
\hline 31.6 & 31.55 & 0.05 & 0.158227848 \\
\hline 40.5 & 40.35 & 0.15 & 0.37037037 \\
\hline & Rata- rata & 0.155 & 0.544584545 \\
\hline
\end{tabular}

Setelah melakukan pengujian sebanyak 10 kali dengan air yang memiliki suhu berbeda, dapat di hitung nilai ratarata error sebesar 0.155. dan dapat di katakan bahwa hasil penggunaan sensor suhu dengan alat ukur termometer efektif karena nilai rata -rata error yang di dapatkan kurang dari 2.

\section{Pengujian putaran ulir dengan takaran pakan}

Pengujian ini di lakukan untuk mengetahui banyak takaran pakan yang keluar dari setiap banyaknya ulir berputar. Dari pengujian ini dapat di ketahui berapa banyak ulir berputar untuk mendapatkan takaran pakan yang di inginkan.

Berdasarkan pengujian yang di lakukan, banyak nya pakan ikan yang keluar setiap 10 putaran dapat dilihat pada pada tabel 5 .

Tabel.5 Hasil uji putaran ulir

\begin{tabular}{ccc}
\hline Banyak putaran & Takaran & Selisih \\
\hline 10 & $32 \mathrm{gr}$ & $32 \mathrm{gr}$ \\
\hline 20 & $60 \mathrm{gr}$ & $28 \mathrm{gr}$ \\
\hline 30 & $92 \mathrm{gr}$ & $32 \mathrm{gr}$ \\
\hline 40 & $130 \mathrm{gr}$ & $38 \mathrm{gr}$ \\
\hline 50 & $160 \mathrm{gr}$ & $30 \mathrm{gr}$ \\
\hline 60 & $190 \mathrm{gr}$ & $30 \mathrm{gr}$ \\
\hline 70 & $218 \mathrm{gr}$ & $28 \mathrm{gr}$ \\
\hline 80 & $245 \mathrm{gr}$ & $27 \mathrm{gr}$ \\
\hline 90 & $272 \mathrm{gr}$ & $27 \mathrm{gr}$ \\
\hline 100 & $302 \mathrm{gr}$ & $30 \mathrm{gr}$ \\
\hline Rata rata selisih pakan & $27 \mathrm{gr}$ \\
\hline
\end{tabular}

Jika di buatkan dalam bentuk grafik, akan memperoleh grafik seperti gambar 8 berikut.

\section{Takaran}

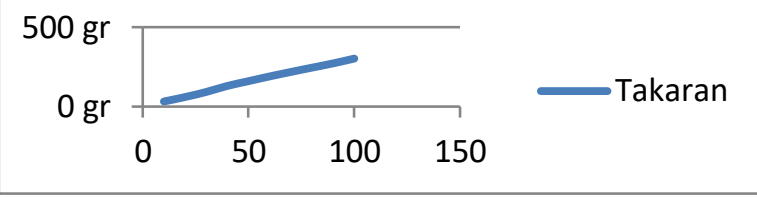

Gambar 8. Grafik putaran ulir dan takran pakan

Sesuai gambar 13 tersebut di hasilkan persamaan :

$\mathrm{Y}=3.0139 * \mathrm{x}+4.3333$

Dimana;

$\mathrm{Y}=$ banyak takaran pakan $(\mathrm{gr})$

$\mathrm{X}=$ banyak putaran ulir

Sehingga, apabila kita menginginkan pakan yang keluar sebanyak $1000 \mathrm{gr} / 1 \mathrm{~kg}$ maka waktu yang di butukan untuk memutar ulir adalah sebesar

$$
\begin{array}{ll}
1000 & =3.0139 * \mathrm{x}+4.3333 \\
\mathrm{X} & =(1000-4.333) / 3.0139 \\
\mathrm{X} & =330.35 \text { putaran }
\end{array}
$$

Jadi, untuk mendapatkan $1 \mathrm{~kg}$ pakan ikan, ulir harus berputar sebanyak 330.35 putaran, namun karena sistem counter pada encoder dalam membaca putaran ulir tidak bisa dalam bentuk desimal, maka dapat kita bulatkan menjadi 331 putaran.

\section{Pengujian kendali fuzzy}

Pengujian fuzzy dilakukan untuk memastikan hasil keluaran fuzzy pada alat sama dengan perhitungan sistem sebenarnya. Setelah melakukan beberapa percobaann di dapatkan hasil seperti tabel 6.

Tabel 6. Hasil takaran menggunakan kendali fuzzy

\begin{tabular}{ccccccc}
\hline Suhu & pH & $\begin{array}{c}\text { Set } \\
\text { pakan }\end{array}$ & $\begin{array}{c}\text { Output } \\
\text { fuzzy }\end{array}$ & $\begin{array}{c}\text { Output } \\
\text { pakan }\end{array}$ & $\begin{array}{c}\text { Output } \\
\text { terukur }\end{array}$ & Selisih \\
\hline $28.05 \mathrm{oC}$ & 7.52 & 200 & $100 \%$ & $200 \mathrm{gr}$ & $200 \mathrm{gr}$ & $0 \mathrm{gr}$ \\
\hline $26.5 \mathrm{oC}$ & 7.1 & 300 & $72.50 \%$ & $217 \mathrm{gr}$ & $210 \mathrm{gr}$ & $7 \mathrm{gr}$ \\
\hline $26.62 \mathrm{oC}$ & 7.25 & 300 & $74.10 \%$ & $222 \mathrm{gr}$ & $230 \mathrm{gr}$ & $8 \mathrm{gr}$ \\
\hline $27.63 \mathrm{oC}$ & 10.5 & 500 & $49.90 \%$ & $249 \mathrm{gr}$ & $260 \mathrm{gr}$ & $11 \mathrm{gr}$ \\
\hline $25.75 \mathrm{oC}$ & 8.01 & 350 & $64 \%$ & $224 \mathrm{gr}$ & $220 \mathrm{gr}$ & $4 \mathrm{gr}$ \\
\hline $25.19 \mathrm{oC}$ & 7.81 & 400 & $59.60 \%$ & $238 \mathrm{gr}$ & $240 \mathrm{gr}$ & $2 \mathrm{gr}$ \\
\hline $28.44 \mathrm{oC}$ & 7.8 & 300 & 100.00 & $300 \mathrm{gr}$ & $300 \mathrm{gr}$ & $0 \mathrm{gr}$ \\
\hline $29.45 \mathrm{oC}$ & 6.56 & 250 & $74.90 \%$ & $187 \mathrm{gr}$ & $200 \mathrm{gr}$ & $13 \mathrm{gr}$ \\
\hline $29.1 \mathrm{oC}$ & 7.83 & 350 & $100 \%$ & $350 \mathrm{gr}$ & $360 \mathrm{gr}$ & $10 \mathrm{gr}$ \\
\hline $28.55 \mathrm{oC}$ & 8.87 & 450 & $61.10 \%$ & $275 \mathrm{gr}$ & $280 \mathrm{gr}$ & $5 \mathrm{gr}$ \\
\hline & & rata rata selisih & & & $6 \mathrm{gr}$ \\
\hline
\end{tabular}

Pada tabel.6 tersebut terlihat bahwa setelah di lakukan percobaan selama $10 \mathrm{kali}$, di dapati rata-rata selisih antara output pakan terhitung dan terukur sebesar 6 . 


\section{KESIMPULAN}

Error kesalahan pengukuran $\mathrm{pH}$ sebesar 2,77 \% dan Error pegukuran sensor suhu $2 \%$ dari alat ukur yang telah di kalibrasi. Untuk makan ikan $1 \mathrm{Kg}$ akan dibutuhkan 331 putaran agar tercapai kebutuhan makan $1 \mathrm{Kg}$ dengan takaran rata-rata sebanyak 302,6 gr setiap 100 putaran ulir dengan dan error pakan yang keluar sebesar $1.03 \%$ dihitung dalam dalam selang waktu 5.77 detik.

\section{REFERENSI}

[1] Ayuningtias, dkk. 2017. “Analisa Perbandingan Logika Fuzzy Metoda Sukamoto, Sugeno dan Mamdani”. Bandung: Universitas Islam Negeri Sunan Gunung Jati.

[2] Caballero Cervantes. 2017. "How to use a pH sensor with Arduino". Di kutip tanggal 20 september di : https://scidle.com/how-to-usea-ph-sensor-with-arduino/

[3] Effendi, H. 2003. Telaah Kualitas Air. Penerbit Kanisius, Yogyakarta

[4] Fitrani,dkk. 2013. "pengaruh pH pada media air rawa terhadap kelansungan hidup dan pertumbuhan benih ikan gabus" Ogan ilir : universitas sriwijaya.

[5] Mulyadi, 2011. " Membuat Aplikasi Android dan Android app inventor" Yogyakarta: Multimedia center publishing

[6] Mustofa Arifin, dkk. 2018. "Pengaruh periode pemuasan terhadap efisiensi pemanfaatan pakan, pertumbuan dan kelulushidupan ikan mas". Semarang, jawa tengah: Universitas Diponegoro

[7] Prabowo Dwi,dkk. 2018."Projek sistim kendali elektronik berbasis arduino". Lampung :AURA.
[8] Primaningtyas,dkk. 2015.’PERFORMA PRODUKSI IKAN LELE YANG DI PERLIHARA DALAM BUDIDAYA BERBEDA".Semarang, Jawa Tengah : Universitas Diponegoro.

[9] Sihombing, Putri Clarita. 2018. "Pengaruh perbedaan 'suhu air terhadap pertumbuhan dan kelansungan hidup benih ikan nila" Sumatera utara: Universitas Sumatera Utara.

[10] Siregar Harva,dkk. 2018. "Alat ukur tingkat keasaman ( pH ) air" Solok : SAIKO

[11] Sudrajat. 2008. "Dasar-dasar fuzzy logic". Bandung: Universitas Padjajaran

[12] Supono, 2015. "Manajemen Lingkungan untuk Akuakultur". Yogyakarta: Plantaxia

[13] Suprianto. 2015. " Sensor penyandi ( Encoder )" Di kutip tanggal 20 september : http://unnes.ac.id/antosupri/sensor-penyandiencoder/

[14] Tucker,Hargreaves. 2004. "Biology and culture of channel catfish". USA: ELSEVIER

[15] Waluyo, agus. 2018. "Pemberi pakan ikan otomatis berbasis IoT menggunakan esp8266".Yogyakarta :UTY

[16] Wibisono.2018. "Rancang bangun alat penebar pakan ikan dengna menggunakan gaya sentripugal tipe apung" Lampung: universitas negeri lampung.

[17] Wibowo,Setyoningsih. 2015. "Penerapan logika fuzzy dalam penjadwalan waktu kuliah". Semarang, Jawa Tengah: Universitas PGRI.

[18] Widyanto,dkk. 2019. "Pengembangan sistim control alat penebar pakan ikan otomatis dengan sumber energy matahari”. Gorontalo : Unsika.

[19] Windriyani, Umi. 2017. "Budidaya ikan lele bioflok". Jakarta: Kementrian Kelautan dan Perikanan 